\title{
IMPACTOS DA UTILIZAÇÃO DE TI EM APOIO À ATIVIDADE LOGÍSTICA DE ABASTECIMENTO DE VIATURAS DA MARINHA DO BRASIL
}

\author{
Marcelo Reis Bezerra \\ Marinha do Brasil (MB) / Pontífice Universidade Católica do Rio de Janeiro (PUC-Rio) \\ marceloreisbezerra@gmail.com \\ Bianca Gomes Soares Gonçalves de Mendonça \\ Marinha do Brasil (MB) / Pontífice Universidade Católica do Rio de Janeiro (PUC-Rio) \\ biancagsoares@bol.com.br
}

\section{RESUMO}

O uso de TI em apoio às atividades logísticas, a constante busca por redução de custos, por maior controle e por aprimoramento na previsão de demanda, com vistas a melhoria do serviço ao cliente e redução do efeito chicote é contínua fonte de análise por parte das empresas e acadêmicos. A Marinha do Brasil, da mesma forma que todas essas empresas, também desenvolve projetos para a melhoria dos seus processos logísticos, sendo abordado neste artigo os impactos positivos decorrentes da implantação de um sistema eletrônico de controle de abastecimento de viaturas, com informação da demanda em tempo real e compartilhamento de dados para uma maior integração da cadeia de suprimento de combustíveis, mitigando os efeitos gerados pelo efeito chicote, dentre outros problemas.

Para atingir o objetivo proposto, o estudo desenvolveu-se sob uma metodologia de pesquisa qualitativa e quantitativa, por meio de um estudo de campo (ex post facto), sendo alcançado como resultado uma redução da ordem de $22 \%$ no consumo de combustíveis automotivo, além da maior visibilidade, integração da cadeia e controle dos abastecimentos realizados. Nesse sentido, o artigo contribui para a redução dos custos logísticos, bem como fornece um modelo capaz de ser adotado por outros órgãos do Governo Federal.

Palavras-Chaves: Marinha do Brasil; Gerenciamento da Cadeia de Suprimento; Compartilhamento de Informações; Efeito chicote; Previsão de Demanda.

\begin{abstract}
The use of IT in support of logistics activities, the constant search for cost reduction, aim to upgrade the control and improvement in forecast demand, with the purpose for update the customer service and reduction of the bullwhip effect is a continual subject of analysis by the companies and universities. The Brazilian Navy, like as all these companies, also develops projects to improve the logistics processes, it being discussed in this article the positive impacts of implementing an electronic control system for fuel supply of vehicles, with demand information in real time and data sharing to further integrating the automotive fuel supply chain, mitigating the effects generated by the bullwhip effect, among other problems.

To achieve this purpose, the study developed under a qualitative and quantitative research methodology through a field of study (ex post facto), and achieved results in a reduction of approximately $22 \%$ in the consumption of automotive fuels, and more visibility, chain integration and control of supplies made. In this sense, the article contributes to the reduction of logistics costs, and provides a model to be adopted by other federal government structures.
\end{abstract}

Keywords:

Brazilian Navy; Supply Chain Management; Information Sharing; Bullwhip effect; Demand forecasting. 


\section{INTRODUÇÃO}

A partir do aumento da importânica do tema defesa na agenda do país, no ínicio deste século, motivada por fatores geo-políticos e econômicos, tais como a publicação da Política Nacional de Defesa e da Estratégia Nacional de Defesa, as descobertas das imensas reservas petrolíferas no pré-sal, que, atualmente, já produzem cerca de 500 mil barris de petróleo ao dia e contam com mais de 10 plataformas em plena operação [25], levando a crescente discussão em nível nacional da importância da Amazônia Azul®, que abrange cerca de 4,5 milhões de $\mathrm{Km}^{2}$, a atuação da Marinha do Brasil (MB) tem sido cada vez mais demandada para a defesa dessa região. Esse cenário cada vez mais complexo, indubitavelmente, exige dos ógãos de apoio logístico da Força constantes transformações na busca por ganhos de eficência, com vistas a melhoria dos seus processos e redução dos custos logísticos, sendo o custo de transporte o mais significativo deles, respondendo por até $60 \%$ dos custos logísticos $[1 ; 10 ; 11 ; 32]$.

As demandas pela função logística de transporte para suporte as demais atividades sempre foi um grande desafio para quaisquer empresas, ai incluídas as Forças Armadas de todo o mundo, principalmente, no que se refere a flexibilidade, aos custos envolvidos e ao controle e auditoria.

No Rio de Janeiro, onde está concentrada mais de $50 \%$ de sua frota e $62 \%$ do consumo de combustível automotivo, a MB possui uma reduzida estrutura de postos de combustíveis próprios para realizar o abastecimento das viaturas, sendo esta sistemática a única solução adotada por muitas décadas e que, atualmente, vem se mostrando ineficiente e antieconômica, em decorrência do desenho da rede (distribuição dos postos) não permitir uma ampla cobertura da sua área de atuação. Tal situação era agravada nos fins de semana com uma redução ainda maior da rede, que gerava deslocamentos desnecessários, maior consumo de combustível e maior emissão de poluentes, observando-se ainda problemas na previsão de demanda, com a falta de informações acerca do real consumo dos postos internos e o conhecido efeito chicote [12].

Diante dos problemas relatados, o Sistema de Abastecimento da Marinha (SAbM), constituído pelo conjunto de órgãos, processos e recursos de qualquer natureza, interligados e interdependentes, estruturado com a finalidade de promover, manter e controlar o provimento do material necessário à manutenção das Forças e demais órgãos navais em condição de plena eficiência [3], sob a coordenação da Diretoria de Abasteciemnto da Marinha (DAbM) e a partir dos estudos realizados, vislumbrou a possibilidade de realizar o forneciemnto de combustíveis utilizando uma sistemática que permitisse a complementação da rede da Marinha pelos postos de empresas privadas, distribuídos em áreas estratégicas no Estado do Rio de Janeiro, cobrindo também os principais eixos de deslocamentos da Força, mantendo os preceeitos fundamentais que já norteiam a Cadeia de Suprimento (CS) de combustíveis da MB, melhorando a visibilidade da demanda da cadeia, fornecendo dados de consumo em tempo real se necessário, a fim de mitigar os males decorrentes da falta de compartilhamento de informações e a deficiência de integração da cadeia $[9 ; 21 ; 22 ; 23]$, cumprindo ainda as imposições previstas na Lei de Licitações [5].

Sob este escopo, o presente estudo tem por objetivo investigar os impactos positivos decorrentes da utilização de TI em apoio à atividade logística de abastecimento de viaturas da MB, por meio das informações disponíveis no ERP da Marinha (SINGRA - Sistema de Informações Gerenciais do Abastecimento), impressões colhidas junto aos usuários do SAbM e um paralelo entre a realidade que se apresentava antes da implantação do sistema eletrônico e o que hoje é visto com a solução implantada.

Ressalta-se ainda que o presente artigo é de suma importância dentro deste contexto, pois o conhecimento gerado com a implantação do projeto na Marinha pode trazer significativos ganhos no caso de adoção por outros órgãos do Governo Federal, com vistas ao aprimoramento da previsão de demanda e a um melhor fluxo de informações ao longo da CS 
que é um dos componentes essenciais para maior integração e colaboração entre os pontos de origem (fornecedores) e os clientes intermediários e finais [7].

\section{REFERENCIAL TEÓRICO}

As primeiras atividades logísticas desenvolveram-se na Grécia antiga em meio às campanhas militares. "Foi na prática da guerra que a logística encontrou seus ensinamentos" [4], sendo os primeiros aprendizados decorrentes de erros e acertos das diversas batalhas. No século XVIII, é percebida nova referência às atividades logísticas, sem ainda constar a utilização do referido termo [24], da mesma forma que CLAUSEWITZ [6], pouco tempo depois, também o faz em sua obra "Da Guerra". O uso efetivo do termo foi encontrado na obra "A Arte da Guerra" [15], sem que, no entanto, fosse feita uma abordagem científica do tema, que só ocorre nos trabalhos de THORPE [28].

As definições apresentadas pelos autores acima seguiam um viés militar, que também pode ser observado na definição do Webster's New Encyclopedic Dictionary apud BALLOU [1], onde "logística é o ramo da ciência militar que lida com a obtenção, manutenção e transporte de material, pessoal e instalações".

Conforme cita BALLOU (2010) apud MIRANDA et al. [21], os estudos iniciais acerca da logística foram desenvolvidos no âmbito militar. Porém, a sua evolução se deve ao setor empresarial, que, na eterna busca de uma maior vantagem competitiva sobre outras empresas, promovem grandes estudos e motivara a comunidade científica nesta mesma tarefa.

Consequência direta desta maior competição, agora em escala global [8], o Gerenciamento da Cadeia de Suprimentos ou Supply Chain Management (SCM) ganha um importante viés de integração de informações e processos, de qualidade e de desempenho [14; $20 ; 26 ; 27]$, gerando implicações positivas no desempenho das empresas, tornando-se um diferencial competitivo [10;11].

O avanço da integração do SCM demanda também uma evolução no mesmo ritmo do uso de TI (Tecnologia da Informação) que apoia as diversas atividades da CS [27], destacando-se alguns momentos nesta evolução, tais como o surgimento do Manufacturing Resource Planning (MRP) I e II, do Electronic Data Interchange (EDI), do Enterprise Resource Planning (ERP), do Vendor Managed Inventory (VMI) e do Collaborative Planning, Forecasting and Replenishment (CPFR) que permitiram uma maior integração da CS, ganhos de eficiência nos processos e aproximação dos clientes [10; 27; 29].

Vários autores $[8 ; 10 ; 11 ; 17 ; 18 ; 19 ; 21 ; 26 ; 27 ; 29]$ citam que essa utilização eficaz de informações logísticas é perseguida ao longo de toda a cadeia, constituindo-se em um fator crítico de sucesso para o seu desempenho e para o nível de satisfação dos clientes [19;20]. Não obstante a tal afirmação, muitos são os fatores que influenciam no desempenho do SCM, destacando-se o nível de serviço praticado, os erros de previsão de demanda, os custos de produção, de estocagem, de armazenagem e de transporte. No caso deste último, para muitas empresas, ele representa o principal custo logístico $[1 ; 10 ; 11]$, sendo então foco de grande atenção destas mesmas empresas.

A atividade de transporte, assim como várias outras atividades logísticas, sofre com a imprevisibilidade da demanda, sendo diversos os métodos/modelos criados para minimizar estes erros de previsão. Um ponto de convergência para um melhor desempenho de qualquer modelo de previsão, apontado pela maioria dos autores, é a maior qualidade dos dados disponíveis para a análise, mitigando assim os problemas decorrentes do efeito Forrester ou efeito chicote ou ainda bullwhip effect [12], que pode ser definido como a variação quantitativa dos pedidos, amplificando a demanda real do consumidor final até ao ponto de origem/fornecedor, passando por toda CS. Neste sentido, o uso de TI, com ou sem emprego de EDI, contribuem de sobremaneira para melhora do desempenho do GCS $[8 ; 17 ; 18 ; 27 ; 31$; 32], seja ela de combustíveis, como no caso deste estudo, ou de qualquer outro produto. 


\section{METODOLOGIA E DESENHO DA PESQUISA}

\subsection{A Metodologia da Pesquisa}

A classificação da presente pesquisa foi desenvolvida a partir dos ensinamentos de VERGARA [30] e GIL [13], em decorrência da importância de seus trabalhos e da sua frequente utilização como orientação aos mais variados projetos científicos.

Segundo a citadas fontes, este projeto é exploratório, pois não foram identificados trabalhos anteriores acerca do uso de TI em apoio à atividade logística de abastecimento de viaturas, no âmbito das Forças Armadas, sobretudo enfatizando os ganhos em termos de controle e redução de custos.

Quanto aos meios, segundo VERGARA [30] e, quanto as fontes, segundo GIL [13], esta pesquisa é classificada como de campo (ex post facto), guardando ainda alguns aspectos relacionados ao estudo de caso, pois foram utilizados dados reais decorrentes da implantação do projeto de controle total de frota na Marinha do Brasil, conduzido pela Diretoria de Abastecimento da Marinha (DAbM), tendo como gerente do projeto um dos autores.

Quanto a abordagem, segundo GIL [13], a pesquisa possui abordagem quantitativa e qualitativa, pois além de analisar os aspectos numéricos relacionados a amostra selecionada, também são considerados aspectos atinentes a tendências ou atitudes, bem como aspectos relacionados com a observação e experiências dos autores deste trabalho.

Em relação ao método científico, como nos ensina LAKATOS e MARCONI [16], não existe uma única forma de raciocínio que conduz as respostas científicas buscadas. Em muitos casos, faz-se mister a combinação dos diversos métodos (indutivo, dedutivo, hipotético-dedutivo, fenomenológico, etc) que nos trás maior clareza na compreensão dos fatos estudados, sendo esta a ideia adotada ao longo deste trabalho. A escolha do melhor método científico é, então, definida a partir dos objetivos/questões para os quais buscamos as resposta [33], ressalvando a possibilidade de combinação de métodos já citadas. Assim, para o presente trabalho, foram utilizados estudo de caso e levantamento de dados no SINGRA (ERP da Marinha).

\subsection{O Desenho da Pesquisa}

A Marinha possui as suas viaturas administrativas, de apoio as atividades logística de transporte e operativas espalhadas em todo o país. Entretanto, a maior concentração destas está no Estado do Rio de Janeiro (RJ), com cerca de 1,5 mil viaturas, que respondem por 62\% do consumo de combustíveis automotivos da Força, como exposto na tabela 1. Em virtude desta maior complexidade e quantidade de meios, bem como o fato de responderem sozinhas pela parcela mais significativa do maior consumo de combustíveis, o presente artigo limitarse-á aos dados relacionados as viaturas sediadas no Estado do RJ:

TABELA 1 - Planejamento das Aquisições de Combustíveis Automotivo da MB para 2013 a 2017.

\begin{tabular}{|c|c|c|c|}
\hline UF & Discriminação do material & Quantidade (L) & Percentual \\
\hline RJ & $\begin{array}{l}\text { Óleo Diesel Automotivo, Gasolina Comum e Álcool } \\
\text { Hidratado. }\end{array}$ & 5.472 .000 & 62,2 \\
\hline $\mathrm{BA}$ & Óleo Diesel Automotivo e Gasolina Comum. & 444.000 & 5,0 \\
\hline $\mathrm{RN}$ & $\begin{array}{l}\text { Óleo Diesel Automotivo, Gasolina Comum e Álcool } \\
\text { Hidratado. }\end{array}$ & 384.000 & 4,4 \\
\hline PA & Óleo Diesel Automotivo e Gasolina Comum. & 660.000 & 7,5 \\
\hline AM & $\begin{array}{l}\text { Óleo Diesel Automotivo, Gasolina Comum e Álcool } \\
\text { Hidratado. }\end{array}$ & 456.000 & 5,2 \\
\hline MS & $\begin{array}{l}\text { Óleo Diesel Automotivo, Gasolina Comum e Álcool } \\
\text { Hidratado. }\end{array}$ & 214.000 & 2,4 \\
\hline $\mathrm{RS}$ & $\begin{array}{l}\text { Óleo Diesel Automotivo, Gasolina Comum e Álcool } \\
\text { Hidratado. }\end{array}$ & 452.000 & 5,1 \\
\hline DF & $\begin{array}{l}\text { Óleo Diesel Automotivo, Gasolina Comum e Álcool } \\
\text { Hidratado. }\end{array}$ & 720.000 & 8,2 \\
\hline Total & Total de Combustíveis Automotivos & & 100 \\
\hline
\end{tabular}
Fonte: Adaptado de www.comprasnet.gov.br, Edital 41/2012 do COMRJ. 
$\mathrm{Na}$ constante busca de melhoria dos processos logísticos da Marinha, vislumbrou-se a possibilidade de adoção de um sistema eletrônico para controle, acompanhamento e autorização do abastecimento de suas viaturas que, atualmente, pode ser encontra semelhança com sistemas utilizados por outras organizações civis, mas que não existe em nenhum órgão público federal, principalmente, pelas limitações impostas pela Lei de Licitações [5], sendo denominado Controle Total de Frotas (CTF), nomenclatura também usualmente utilizada pela iniciativa privada no que se refere a este tipo de sistema, configurando, um exemplo da utilização da técnica de benchmarking, ou seja, a internalização de uma boa prática privada e de comprovado sucesso dentre as empresas com grandes frotas de veículos, para a esfera do Governo Federal.

Anteriormente a implantação do CTF, a empresa vencedora do certame licitatório distribuía o combustível que seria utilizado pelas viaturas da MB no Rio de Janeiro, para os postos que se localizavam dentro de Organizações Militares da Marinha (OM), sendo estas as únicas alternativas de fornecimento de combustível, sendo ainda a autorização para estes abastecimentos processada em papel, a partir da impressão da RMC (Requisição de Material para Consumo) e a sua apresentação no posto no momento do abastecimento.

Aqui, vale a observação e a identificação do problema, pois a distribuição geográfica destes postos não permitia uma ampla cobertura da área de atuação das viaturas, já que nenhum destes locais de abastecimento cobria regiões como a Zona Sul, Zona Oeste, Baixada Fluminense, regiões adjacentes a Niterói, grandes eixos de deslocamento no sentido São Paulo, região serrana e costa verde, dentre outros e, considerando a localização das OM, não seria economicamente viável a criação de novos postos da $\mathrm{MB}$ para atender a estas áreas não cobertas pela rede. Aos fins de semana e feriados, esta situação se agravava com o funcionamento apenas do posto localizado no DepCMRJ, na Ilha do Governador. Esta situação exigia, por exemplo, que uma viatura que saísse do Centro do RJ, para um trabalho na zona Oeste, tivesse que se deslocar até a Ilha do Governador para abastecimento.

Com as características de transito intenso observadas no Rio de janeiro, mesmo aos fins de semana, registravasse um grande gasto adicional de combustível, bem como a decorrente emissão de poluentes, para atender a estes deslocamentos extras, teoricamente, ineficientes e desnecessários.

A Marinha, como todas as empresas que trabalham com previsão de demanda, ainda enfrenta o grande desafio da correta estimativa de consumo para efetuar as suas solicitações as fornecedores, nas quantidades e mix de produto corretos (gasolina, álcool e diesel), de forma a mitigar o efeito chicote [12] e evitar o stock out de combustível. O problema do dimensionamento algumas vezes se apresentava alheio a vontade do militar que estava dirigindo o veículo, pois o consumo de combustível pode variar dependendo das condições de tráfego. Assim, os problemas do dimensionamento, flexibilidade e das distâncias a serem percorridas, não eram os únicos que se apresentavam para a Marinha, havia também a dificuldade de controlar a quantidade exata que saia da bomba de combustível e entrava no tanque da viatura. Esta operação algumas vezes apresentava um controle ineficiente e vez por outra gerava graves problemas administrativos quando não raramente eram identificadas diferenças entre os controles e a quantidade física em estoque nos postos da $\mathrm{MB}$, existindo também uma grande demanda por aprimoramento da sistemática de controle interno e auditoria, sendo o uso de compartilhamento de informações, e acesso a dados em tempo real, fundamental para mitigar estes problemas [2].

Em 2012, a partir de um projeto piloto que contou com a instalação do CTF em 10 (dez) viaturas da Marinha, com vistas a desenvolver as necessárias alterações no ERP da Marinha, o conhecimento das possibilidades e limitações do sistema, bem como a exequibilidade e adequabilidade de adoção do mesmo, em consonância com as características da CS de combustíveis da Marinha, foi iniciado a implantação do referido sistema.

Ainda no ano de 2012, foi elaborado um modelo de edital de licitação e contrato 
inovador, já que não existe o CTF implantado no âmbito do governo federal, em conformidade com a Lei de Licitações [5].

Vencidas as etapas preparatórias de testes, alterações nos sistemas, normatização, negociação com empresas, etc, em agosto de 2013, foram iniciadas as instalações dos equipamentos nas viaturas e postos da Marinha e, a partir de janeiro de 2014, o projeto alcançou a sua maturidade.

Assim, os dados comparativos para avaliação do sistema envolveram o período de janeiro a julho de 2014, onde o sistema já havia adquirido a sua plenitude e o período de janeiro a julho de 2013, onde o sistema não existia na MB e a equivalência dos meses elimina as variáveis de sazonalidade, concentração de tarefas ao longo do ano e outros, dando uma perspectiva fidedigna dos ganhos obtidos.

Quanto à tecnologia utilizada, esta se apresenta basicamente na instalação de um equipamento na viatura que será abastecida e outro no local de abastecimento. Estes equipamentos, que não apresentam nenhuma interferência humana, são os responsáveis pelo fornecimento das informações relacionadas aos abastecimentos, entre os postos onde estes se realizam e os servidores localizados na Diretoria de Abastecimento da Marinha (DAbM), órgão que obtém e controla o combustível adquirido pela MB, por meio do ERP da Marinha (SINGRA), permitindo ainda o acesso a estes dados por todos os usuários e gestores, conforme o nível de acesso determinado. Não obstantes a necessidade de instalação dos equipamentos nos veículos, mesmo no caso do abastecimento de equipamentos/veículos que não possuem o CTF, como um cortador de grama, por exemplo, o sistema registra o horário, local, quantidade e tipo de combustível fornecido, ficando o técnico do posto responsável por indicar a aplicação/finalidade de tal abastecimento, dando flexibilidade, confiabilidade e detalhado controle à Marinha.

Nesta cadeia de suprimentos, os postos de combustíveis internos (postos da MB) e os postos de combustíveis externos (postos de empresas privadas) são os varejistas e, a partir deste ponto da cadeia, foram implantados os sistemas de controles baseados em TI, para maior visibilidade da demanda da cadeia em tempo real $[22 ; 23 ; 31]$ e maior controle dos abastecimentos. O SAbM atua como órgão coordenador da CS de combustíveis, sendo o foco do fluxo de informações, como mostra a Figura 1:

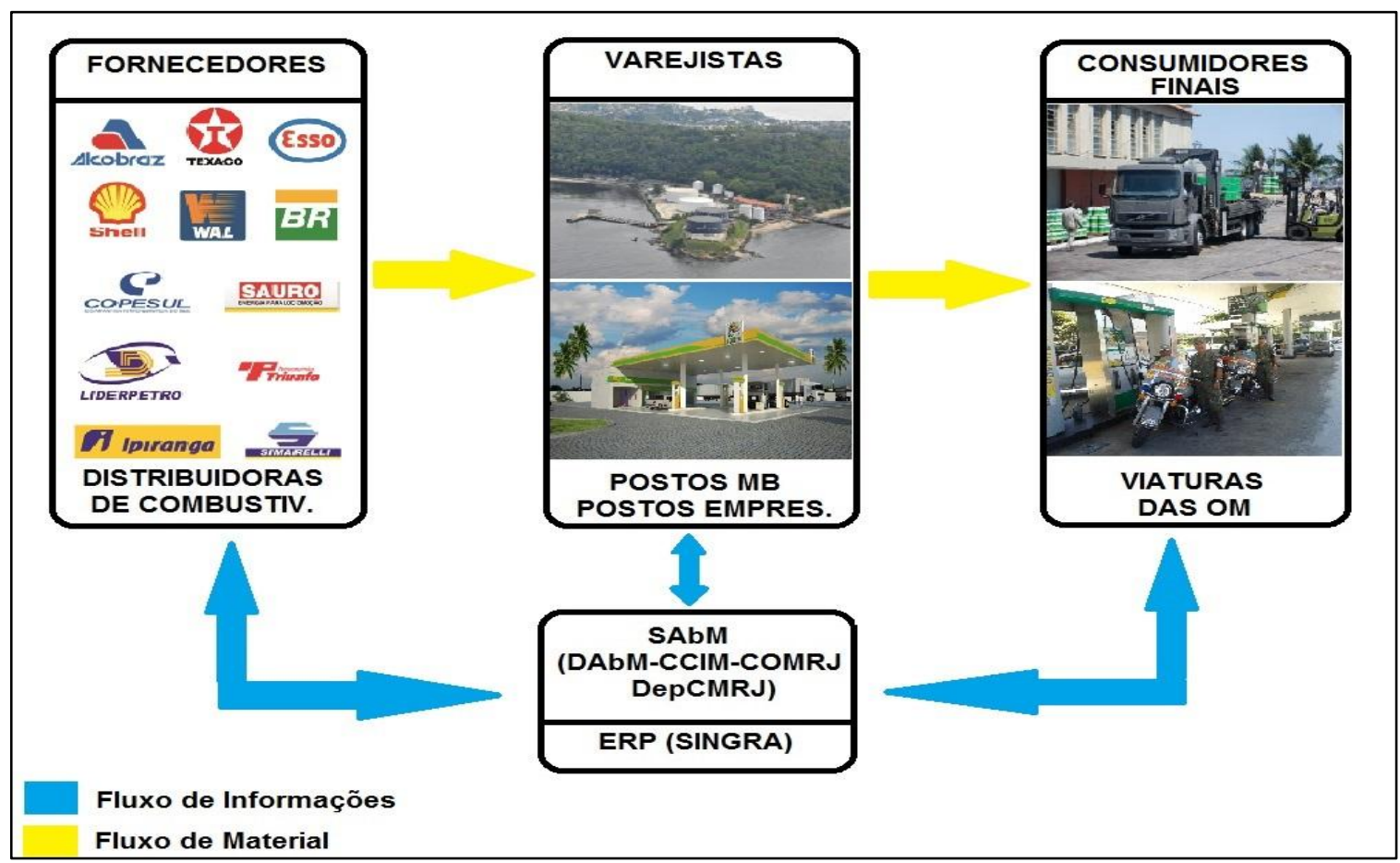

FIGURA 1. Desenho da Cadeia de Suprimentos de Combustíveis Automotivos da MB. Fonte: os Autores. 
A partir da análise detalhada, anteriormente, foram efetuados os estudos acerca dos impactos decorrentes da utilização da TI em apoio à atividade logística de abastecimento de viaturas da Marinha do Brasil, com vistas a estimar os ganhos obtidos. Também se analisou o efeito Forrester [12] ao longo da cadeia.

\section{ESTUDO DE CASO DA IMPLANTAÇÃO DO SISTEMA DE CONTROLE ELETRÔNICO DE ABASTECIMENTOS}

Por meio do ERP (SINGRA), as Organizações Militares Fornecedores (OMF), ou seja, aquelas que possuem postos de combustíveis que atendem as viaturas da Marinha, emitem as requisições de combustíveis (RCL), que, após análise e aprovação do Centro de Controle de Inventário (CCIM) são enviadas as distribuidoras contratadas pela Marinha. Vinculadas as RCL, são geradas ordens de compras pelo Centro de Obtenção da Marinha no Rio de Janeiro (COMRJ), a fim de permitir o posterior pagamento às empresas fornecedoras de combustíveis.

A fim de realizar o abastecimento de suas viaturas, as Organizações Militares Consumidoras (OMC) geravam então uma requisição de material para consumo (RMC), constando, dentre outras informações, o tipo de combustível a ser recebido, a quantidade desejada e o custo total do produto que é abatido da conta da OMC no SINGRA.

Essas RMC eram então assinadas pelo Oficial responsável pelas viaturas e o motorista conduzia a viatura ao posto, apresentado a RMC gerada. $\mathrm{O}$ técnico que trabalha no posto recebia o documento, fazia o fornecimento do combustível e registrava no mesmo documento os valores reais abastecidos, que, invariavelmente, diferiam do registrado na RMC, pois, dificilmente, a estimativa de quantos litros ainda cabia no tanque da viatura que seria abastecida era concretizada.

Nos dias que se seguiam, as quantidades reais de combustível fornecidas eram registradas no ERP, com vistas a realizar o acerto dos abatimentos feitos nas cotas das OMC.

Como era de se esperar, por vezes ocorriam erros no registro das quantidades reais que haviam sido abastecidas para cada uma das RMC, bem como no registro destas no banco de dados do ERP (SINGRA).

As decisões quanto aos níveis de estoque nas OMF, bem como a estratégia de reposição de estoque para os distintos itens, são realizadas pelos gerentes do CCIM e/ou encarregados dos postos, baseadas nas informações disponíveis, por vezes imprecisas.

A partir deste cenário e dos estudos realizados foi então iniciada a implantação do sistema de controle eletrônico de abastecimento, denominado CTF, conforme denominação já observada no meio civil/empresarial.

O CTF é um sistema desenvolvido com o objetivo de permitir o controle de todas as informações atinentes ao abastecimento de veículos, seja em postos internos (postos da MB), seja em postos externos (postos privados).

A tecnologia utilizada pelo sistema consiste na instalação de um equipamento no veículo a ser abastecido, denominado Unidade Veicular (UVE) e outro equipamento no posto abastecedor, denominado ZIMUX. Tais equipamentos são responsáveis por trocar todas as informações relativas aos abastecimentos, através do uso de EDI, entre os postos onde estes ocorrem e os servidores que armazenam e controlam os dados.

De forma a viabilizar economicamente o projeto para as empresas fornecedoras do sistema (retorno do investimento inicial necessário para instalação dos equipamentos $\mathrm{x}$ preço do combustível a ser cobrado à MB), existia a necessidade de reduzir a quantidade de postos internos de baixo consumo, abaixo de 10.000 litros/ano, em virtude dos custos de instalação dos equipamentos. Entretanto, estes foram mantidos, em decorrência de fatores estratégicos, e foi incluído no projeto o fornecimento de combustíveis em nível nacional, mesmo sendo o CTF instalado, inicialmente, só no Estado do RJ, obtendo assim o ganho de escala necessário à viabilidade do projeto. 
Foi montado um modelo de licitação, baseado na legislação vigente [5], que autoriza a subcontratação de parte do serviço, neste caso específico do sistema de controle eletrônico, pela empresa vencedora. Assim, qualquer que fosse a distribuidora vencedora do certame, a mesma poderia subcontratar o sistema de controle eletrônico que ela já trabalha e que é compatível com o seu sistema, o que era essencial para a utilização da rede de postos privados. A PETROBRAS, por meio de sua subsidiária BR Distribuidora AS, foi vencedora do processo licitatório sendo então definidos todos os parâmetros necessários à integração dos sistemas.

A instalação das Unidades Veiculares (UVE) nas viaturas da MB foi realizada em uma Base da Marinha, a fim de ser mantido o controle de todo o processo, bem como possibilitar a coordenação de centenas de viaturas que receberam o dispositivo, já tendo sido detalhado, anteriormente, os motivos da escolha do Rio de Janeiro para implantação do projeto.

\subsection{Os Ganhos a partir do Novo Sistema}

Com as alterações realizadas no ERP (SINGRA), foi dispensada a emissão e assinatura de requisição de material para consumo (RMC) pelos clientes, já que agora o sistema verifica em tempo real se a viatura pertence a uma organização da Marinha, se a mesma possui saldo para o abastecimento e se existe alguma outra restrição ao fornecimento do combustível. Concluído o abastecimento, o sistema envia as informações ao ERP, sendo este abastecimento registrado no sistema e abatido na cota da organização militar proprietária da viatura.

Tal procedimento extinguiu a emissão de milhares de documentos ao ano, bem como erros decorrentes do registro manual que era feito no sistema, passando ainda a disponibilizar, em tempo real as informações de consumo, que antes podiam levar semanas até que todos os documentos fossem incluídos no sistema.

Todas estas informações são ainda disponibilizadas via intranet/internet aos gestores dos postos de combustíveis e seus auxiliares, bem como aos gerentes dos níveis superiores da CS.

Nos finais de semana e feriados, quando a única estrutura que realizava o abastecimento no Rio e região metropolitana era o Depósito de Combustíveis da Marinha no Rio de Janeiro (DepCMRJ), localizado na Ilha do Governador, a Marinha passou a contar com uma grande rede de postos privados, reduzindo significativamente os deslocamentos, bem como dando maior flexibilidade nas operações planejadas.

No caso de veículos com autonomia reduzida, como, por exemplo, as motocicletas de escolta, as famosas Harley-Davidson dos batedores da Marinha, que possuem raio de ação de cerca de $150 \mathrm{~km}$, o CTF passou a ser um elemento essencial no planejamento, viabilizando operações que antes dependiam do acompanhamento de um caminhão tanque e/ou galões de combustível pré-posicionados em áreas específicas.

Além de todos os ganhos de eficiência em termos de processos e integração da CS de combustível já expostos, bem como os ganhos operacionais, sobretudo dos veículos com autonomia reduzida, que por si só justificam a grande importância do projeto em lide, há que se registrar também os ganhos obtidos em termos de custos logísticos, decorrentes, entre outros fatores, da redução do consumo de combustível, em parte pela maior eficiência nos deslocamentos das viaturas como já citado, em parte pelo maior controle que hoje é feito, detalhando cada abastecimento realizado pela Marinha com margem de erro de apenas $0,1 \mathrm{~L}$ por fornecimento.

Mesmo nos casos onde o veículo não possui o CTF instalado, o militar de serviço no posto tem que liberar o abastecimento por senha própria, permitindo assim que, ao fim do dia ou a qualquer momento desejado, o encarregado do posto realize uma auditoria, cobrando que o operador do posto justifique os abastecimentos liberados por ele, estando todas as 
informações deste abastecimento registradas no relatório de fornecimentos (com a indicação da quantidade, do horário e do tipo de combustível fornecido), constando ainda do relatório a observação de que o abastecimento foi liberado por meio de senha do operador do posto e não automaticamente pelo sistema.

Como a escolha da utilização de um veículo para uma tarefa de transporte obedece, dentre outros critérios, a disponibilidade do veículo para o serviço, por vezes um veículo movido a gasolina pode realizar uma tarefa que, normalmente, seria de um veículo movido a diesel e vice-versa. No caso do álcool e da gasolina, com a popularização dos motores flex, essa substituição é ainda mais clara, podendo a redução do consumo de um combustível ser "mascarada" e/ou anulada pelo aumento do outro. Assim, o consumo de combustível foi considerado de forma consolidada, a fim de minimizar as distorções citadas.

O gráfico da figura 2 a seguir apresenta o consumo consolidado de combustível (gasolina, álcool e diesel) no período de janeiro a julho de 2013, quando não existia o CTF na Marinha e no período de janeiro a julho de 2014, quando o CTF já estava em plena operação, após o período de instalação de equipamentos e adequação dos sistemas realizados:

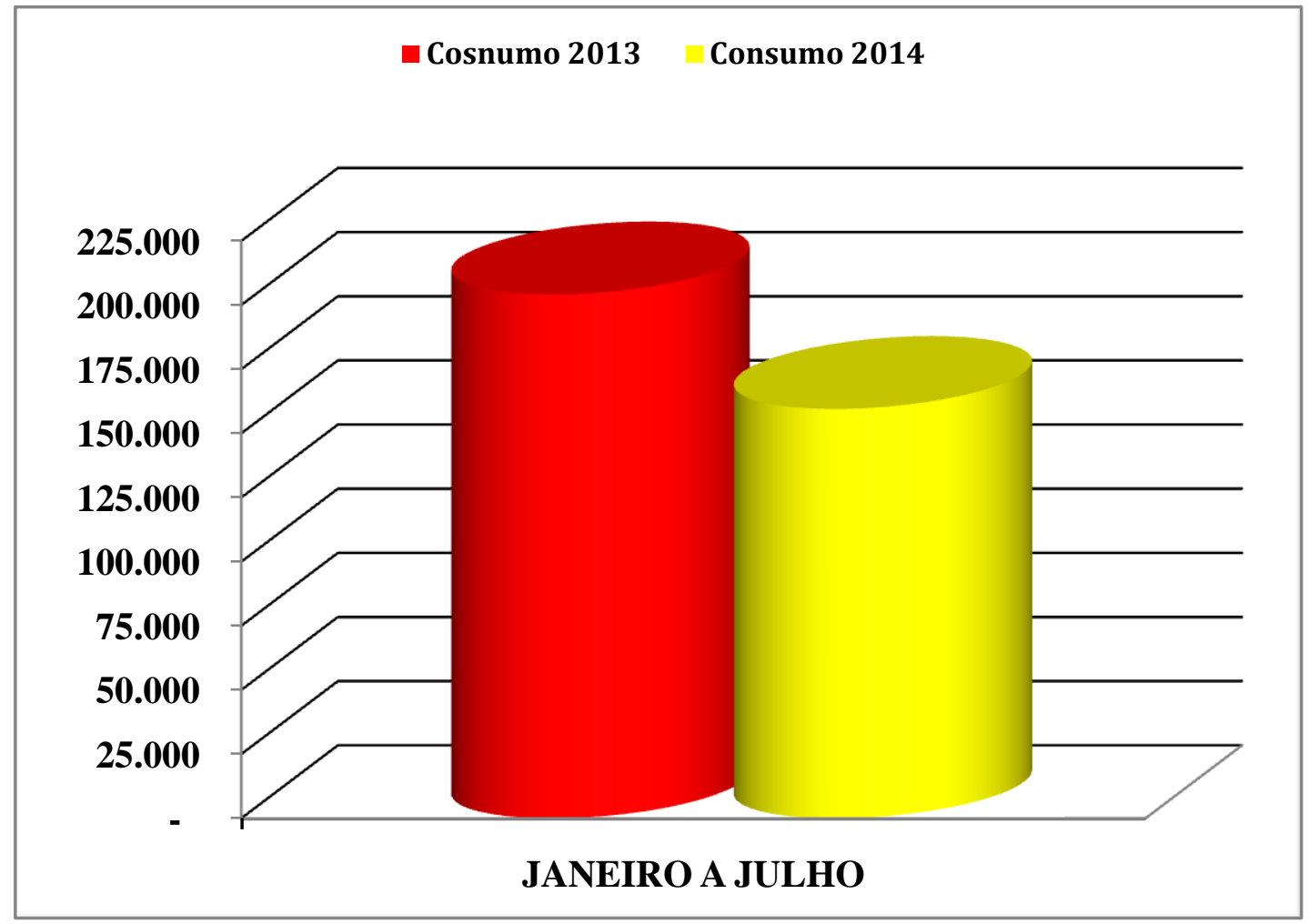

FIGURA 2. Consumo de combustível automotivo da Marinha no Rio de Janeiro. Fonte: Adaptado do SINGRA (2014).

Com o conhecimento em tempo real da demanda de combustível, o que antes poderia levar semanas para ser obtido, com as imprecisões já citadas, o efeito chicote também foi minimizado [10;11], contribuindo para a redução dos custos de armazenagem e de SCM, como nos ensina WANKE [31], cabendo ao CCIM os ajustes quantitativos e qualitativos, que já estão em andamento, junto aos fornecedores.

\section{CONCLUSÃO}

Foram expostos benefícios da utilização de TI em apoio à atividade logística de abastecimento de viaturas da MB, com ganhos no âmbito da integração da CS, do controle dos fornecimentos de combustíveis, da redução dos custos logísticos, da melhoria dos processos com a redução dos erros de registros no sistema e a disponibilização da informação 
em tempo real e da redução da carga burocrática. Além destes benefícios de ordem logística, observam-se ganhos em termos operacionais com uma maior flexibilidade para o emprego das viaturas, sobretudo aquelas de autonomia reduzida, como destaque para o caso das motocicletas de escolta.

A redução dos custos de armazenagem e a diminuição do efeito chicote ao longo da cadeia também são ganhos significativos observados, mas de difícil mensuração, em decorrência das características da CS de combustíveis da MB.

Outro aspecto importante é a posição de vanguarda da Marinha entre os órgãos da administração pública federal, já que sistema semelhante só é encontrado no meio privado ou em nível da administração pública estadual, que não estão sujeitos às limitações da Lei de Licitações [5].

A partir desta experiência da Marinha e dos significativos ganhos obtidos, outros órgãos públicos podem melhorar os seus processos logísticos de abastecimento de viaturas, dando maior visibilidade à sociedade da utilização dos recursos públicos e economizando importante parcela do orçamento que é empregado nesta atividade.

Com a maior demanda de apoio da Marinha para defesa da Amazônia Azul® e outras atividades no cenário nacional e internacional, o sistema de apoio logístico vem atuando em um ambinete cada vez mais complexo [32], exigindo constantes evoluções na busca por ganhos de eficência e redução dos custos logísticos, o que foi plenamente alcançado por meio do projeto apresnetado.

Como sugestão de estudos futuros, fica a proposta de analisar/estimar os ganhos observados na redução do efeito chicote e nos custos de armazenagem, decorrentes da implantação do CTF na MB.

\section{REFERÊNCIAS BIBLIOGRÁFICAS}

[1] BALlOU, R. H. Gerenciamento da Cadeia de Suprimentos/Logística Empresarial. 5 ed. Porto Alegre: Bookman, 2006.

[2] BHATTACHARYA, R. BANDYOPADHYAY, S.; A review of the causes of bullwhip effect in a supply chain. The International Journal of Advanced Manufacturing Technology. v. 54, p. 1245-1261, 2011.

[3] BRASIL. Secretaria-Geral da Marinha. SGM-201: Normas para o Abastecimento na Marinha, 6 rev., Brasília, DF, 2009.

[4] _ Estado-Maior da Armada. EMA-400: Manual de Logística da Marinha, 2 rev., Brasília, DF, 2003.

[5] . Lei n. ${ }^{\circ}$ 8.666, de 21 de junho de 1993. Regulamenta o art. 37, inciso XXI, da Constituição Federal, institui normas para licitações e contratos da Administração Pública e dá outras providências. Presidência da República. Disponível em: <http://www.planalto.gov.br/ccivil_03/Leis/L8666cons.htm>. Acesso em: $12 \mathrm{dez} 2014$.

[6] CLAUSEWITZ, C. V. Da Guerra. Alemanha, 1832. Disponível em: <https://www.egn.mar.mil.br/arquivos/cepe/DAGUERRA.pdf>. Acesso em: $13 \mathrm{dez}$ 2014.

[7] COUNCIL OF SUPPLY CHAIN MANAGEMENT PROFESSIONALS. Terms and Glossary. $\quad$ Ago. 2013. $\quad$ Disponível em <http://cscmp.org/sites/default/files/user_uploads/resources/downloads/glossary2013.pdf>. Acesso em: $15 \mathrm{dez} 2014$.

[8] DORNIER, P. P.; ERNST, R.; FENDER, M.; KOUVELIS, P. Logística e operações globais: texto e casos. 7 reimpr. São Paulo: Atlas, 2009.

[9] FAN, C. Y.; FAN, P. S; CHANG, P. C. A system dynamics modeling approach for a 
military weapon maintenance supply system. International Journal Products Economics. n 128, p.457-469, 2010.

[10] FIGUEIRDO, K. F.; FLEURY, P. F.; WANKE, P. F. (organizadores). Logística e gerenciamento da cadeia de suprimentos: planejamento do fluxo de produtos e dos recursos. 4. reimpr. São Paulo: Atlas, 2008.

[11] FLEURY, P. F.; WANKE, P.; FIGUEIRDO, K. F. (organizadores). Logística empresarial: a perspectiva brasileira. 11 reimpr. São Paulo: Atlas, 2009.

[12] FORRESTER, J. W. Industrial dynamics: a major breakthrough for decision makers. Harvard Business Review. v. 36, n. 4, p. 37-66, 1958. Disponível em: <https://hbr.org/archive-toc/3584>. Acesso em: 10 jan 2014.

[13] GIL, A. C. Como elaborar projetos de pesquisa. 4. ed. São Paulo: Atlas, 2002.

[14] GUNASEKARAN, A.; NGAI, E. W. T. Decision support systems for logistics and supply chain management. Decision Support Systems, n. 52, p. 777-778, 2012.

[15] JOMINI, A. H. A Arte da Guerra. França, 1836.

[16] LAKATOS, E. M.; MARCONI, M. A. Fundamentos da Metodologia Científica. 3 ed. São Paulo: Atlas, 1991.

[17] LI, C. Controlling the bullwhip effect in a supply chain system with constrained information flows. Applied Mathematical Modeling. v. 37, n. 4, p. 1897-1909, 2013.

[18] LI, C.; LIU, S. A robust optimization approach to reduce the bullwhip effect of supply chains with vendor order placement lead time delays in an uncertain environment. Applied Mathematical Modeling. v. 37, n. 3, p. 707-718, 2013.

[19] LOW, C.; CHEN, Y. H. A model measurement system for collaborative supply chain partners. Journal of Manufacturing Systems. v. 32, p. 180-188, Jan. 2013. Disponível em <http://www.sciencedirect.com/science/article/pii/S0278612512000386>. Acesso em: 14 dez 2014.

[20] MELLAT-PARAST, M., Supply Chain quality management: an inter-organizational learning perspective. Supply Chain Quality Management. P 511-529, 2012.

[21] MIRANDA, R. F. Q; BEZERRA, M. R.; GIGANTE, T. C.; DUARTE, D. L. Impactos da utilização de Sistema de Informação Logístico no compartilhamento de informações na Cadeia de Suprimento de Sobressalentes da Marinha do Brasil. In: Simpósio de Pesquisa Operacional \& Logística da Marinha, Rio de Janeiro: SPOLM 2014, p. 395-406, 2014.

[22] MOON, S.; HICKS, C.; SIMPSON, A. The development of a classification model for predicting the performance of forecasting methods for naval spare parts demand. Int. J. Production Economics. n 143, p 449-454, 2013.

[23] MOON, S.; HICKS, C.; SIMPSON, A. The development of a hierarchical forecasting method for predicting spare parts demand in the South Korean Navy - A case study. Int. J. Production Economics. n 140, p 794-802, 2012.

[24] NOVAES, A. G. Logística e gerenciamento da cadeia de distribuição: estratégia, operação e avaliação. 2 ed. Rio de Janeiro: Elsevier, 2004.

[25] PETROBRAS. O Pré-Sal é uma realidade. Disponível em $<$ http://www.petrobras.com.br/pt/nossas-atividades/areas-de-atuacao/exploracao-eproducao-de-petroleo-e-gas/pre-sal/?gclid=CITv4_CG9sICFUsR7AodknAAnQ>. Acesso em: $11 \mathrm{dez} 2014$. 
[26] RUSSEL, S. H. Supply chain management: more than integrated logistics. Air Force Journal of Logistics. v. 31, n. 2, p. 55-63, 2007.

[27] SIMCHI-LEVI, D.; KAMINSKY, P.; SIMCHI-LEVI, E. Managing the supply chain: the definitive guide for the business professional. New York: McGraw-Hilll, 2003.

[28] THORPE, G. C. Logística Pura: a ciência da preparação para a guerra. Newport, RI, 1917.

[29] TURBAN, E.; McLEAN, E.; WETHERBE, J. Tecnologia da Informação para Gestão. Porto Alegre: Boowman, 2004.

[30] VERGARA, S. C. Projetos e relatório de pesquisa em administração. 14. ed. São Paulo: Atlas, 2013.

[31] WANKE, P. F. Gestão de Estoques na Cadeia de Suprimento: Decisões e Modelos Quantitativos. São Paulo: Atlas, 2011.

[32] WANKE, P. F.; CORREA, H. L. The relationship between the logistics complexity of manufacturing companies and their supply chain management. Gest. Prod., São Paulo, v. 24, n. 2, Jun. 2014. Disponível em $<$ http://www.scielo.br/scielo.php?script=sci_arttext\&pid=S010365132014000200001\&lng=en \&nrm=iso>. Acesso em: $13 \mathrm{dez} 2014$.

[33] YIN, R. K. Estudo de caso: planejamento e métodos. 4 ed. Porto Alegre: Bookman, 2010. 